\title{
A validated stability-indicating HPLC method for determination of varenicline in its bulk and tablets
}

\author{
Adnan A Kadi, Mostafa S Mohamed, Mohamed G Kassem and Ibrahim A Darwish*
}

\begin{abstract}
A simple, sensitive and accurate stability-indicating HPLC method has been developed and validated for determination of varenicline (VRC) in its bulk form and pharmaceutical tablets. Chromatographic separation was achieved on a Zorbax Eclipse XDB-C8 column $(150 \mathrm{~mm} \times 4.6 \mathrm{~mm}$ i.d., particle size $5 \mu \mathrm{m}$, maintained at ambient temperature) by a mobile phase consisted of acetonitrile and $50 \mathrm{mM}$ potassium dihydrogen phosphate buffer $(10: 90, v / v)$ with apparent $\mathrm{pH}$ of $3.5 \pm 0.1$ and a flow rate of $1.0 \mathrm{ml} / \mathrm{min}$. The detection wavelength was set at 235 $\mathrm{nm}$. VRC was subjected to different accelerated stress conditions. The degradation products, when any, were well resolved from the pure drug with significantly different retention time values. The method was linear $(r=0.9998)$ at a concentration range of $2-14 \mu \mathrm{g} / \mathrm{ml}$. The limit of detection and limit of quantitation were 0.38 and $1.11 \mu \mathrm{g} /$ $\mathrm{ml}$, respectively. The intra- and inter-assay precisions were satisfactory; the relative standard deviations did not exceed $2 \%$. The accuracy of the method was proved; the mean recovery of VRC was $100.10 \pm 1.08 \%$. The proposed method has high throughput as the analysis involved short run-time ( $6 \mathrm{~min})$. The method met the ICH/FDA regulatory requirements. The proposed method was successfully applied for the determination of VRC in bulk and tablets with acceptable accuracy and precisions; the label claim percentages were $99.65 \pm 0.32 \%$. The results demonstrated that the method would have a great value when applied in quality control and stability studies for VRC.
\end{abstract}

\section{Background}

Varenicline (VRC, Figure 1); 7,8,9,10-tetrahydro-6,10methano- $6 H$-azepino $[4,5-g]$ quinoxaline $(2 R, 3 R)$, is a novel agent that is a centrally acting as a highly selective partial agonist for the nicotinic acetylcholine receptor [1]. VRC has mixed agonistic-antagonistic properties, thus it has the therapeutic benefit of relieving the symptoms of nicotine withdrawal and cigarette craving during abstinence while blocking the reinforcing effect of nicotine in those who lapse [2-4]. VRC tartrate (Champix ${ }^{\mathbb{B}}$ and Chantix ${ }^{\circledR}$; Pfizer) has been approved by the USAFDA as an aid to smoking cessation [5]. The approved regime of VRC is $1 \mathrm{mg}$ for 12 weeks, starting with a 1 week titration period [6].

The quality of pharmaceutical product of VRC, in terms of purity and stability of the active substance and/

\footnotetext{
* Correspondence: idarwish@ksu.edu.sa

Department of Pharmaceutical Chemistry, College of Pharmacy, King Saud University, P.O. Box 2457, Riyadh 11451, Saudi Arabia
}

or finished product is vital for the effective and safe delivery of its therapeutic values to the smokers. This is because the presence of impurities and/or potential degradation products may cause changing of chemical, pharmacological, and/or toxicological properties of the active drug entity [7-9]. In general, pharmaceuticals are sensitive to environmental factors such as temperature, humidity, and light. These factors usually vary during manufacturing, transportation, storage, and distribution of the finished product. For these reasons, stability testing of the active substance and the finished product is necessary for providing information about potential degradation products, possible degradation pathways of the drug, compatibility of the drug with the excipients in the finished product, and the long-term effects of the environmental factors on the active drug and its finished products. Results of stability testing are important in developing proper manufacturing process, selecting proper packaging, storage conditions, product's shelf life, and determining the expiration date [10-12]. 


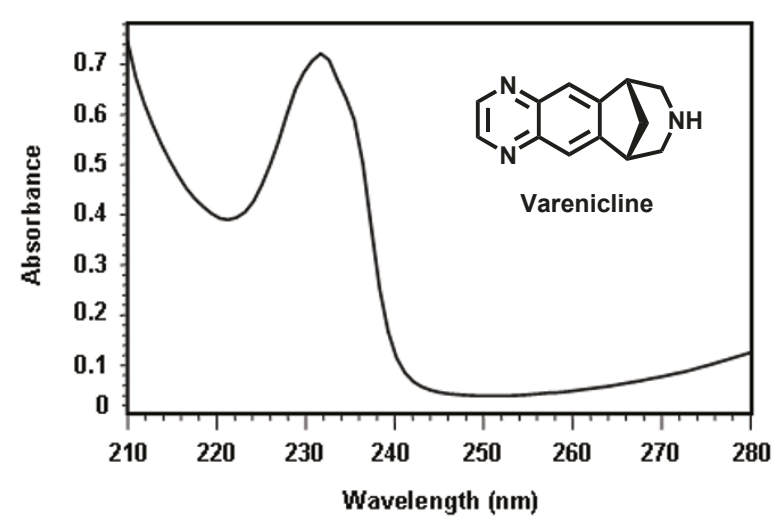

Figure 1 Chemical structure of varenicline (VRC) and its absorption spectrum against water. Concentration of VRC was 10 $\mu \mathrm{g} / \mathrm{ml}$ in water.

Furthermore, the climate is widely varying worldwide, and consequently, the quality of pharmaceutical product of VRC is greatly affected by the change in the environmental factors. As well, VRC-containing tablets are imported from outside of many countries, consequently there is a major concern about its quality after exposure to transportation, storage, and other conditions. Therefore, quality control for VRC-containing tablets is critically concerned in these countries. In literature, only one report has been found describing the separation and quantitation of process-related substances to VRC tartarate [13], however there was no report on the stabilityindicating assay for VRC. For these reasons, a stabilityindicating method for determination of VRC in its bulk drug and pharmaceutical tablets is essential, particularly, such methods have become an important aspect of any analytical method validation and a part of ICH guidance for pharmaceutical industry [12].

The present study describes, for the first time, the development and validation of a stability-indicating HPLC method for stability evaluation and quantitative determination of VRC in the presence of its degradation products.

\section{Results and Discussion}

\section{Method Development}

The initial method development was conducted on pure drug using working standards solution protected from light. The light absorption characteristics of VRC are not available in literature, therefore its ultraviolet (UV)absorption spectrum was recorded for selecting the proper maximum absorption peak $\left(\lambda_{\max }\right)$. As shown in Figure 1 , the $\lambda_{\max }$ of VRC is located at $235 \mathrm{~nm}$. Therefore, the detection wavelength of the detector was set at this wavelength. Actual chromatographic conditions were established after number of preliminary experiments for selecting the proper mobile system. Different mobile phase systems were tested, and the selection of the proper system depended on its ability to give good separation between the pure VRC and its possible impurities and/or degradation products. Acceptable separation was achieved on Zorbax Eclipse XDB-C8 column (150 $\mathrm{mm} \times 4.6 \mathrm{~mm}$ i.d., particle size $5 \mu \mathrm{m}$ ) using a mobile phase composed by acetonitrile: $0.05 \mathrm{M}$ potassium monobasic phosphate buffer of $\mathrm{pH} 3.5(10: 90, v / v)$ pumped with a flow rate of $1 \mathrm{~m} / \mathrm{min}$. The column temperature was kept constant at $25 \pm 2^{\circ} \mathrm{C}$. Under these chromatographic conditions, the run time of the sample was 6 min, and the retention time of VRC was $3.03 \pm 0.06 \mathrm{~min}$ $(\mathrm{n}=3)$ (Figure 2A).

\section{Method Validation \\ Linearity and Sensitivity}

Using the above-mentioned optimum chromatographic conditions, three independent calibration curves were constructed correlating the detector signals with the corresponding VRC concentrations. Each curve was generated by 7 -concentration points; each concentration was injected in triplicates). Regression analysis for the results was carried out using the least-square method. The standard deviation values of each concentration point (triplicates) did not exceed $2 \%$. The results revealed a good linear calibration fit in the range of 2$14 \mu \mathrm{g} / \mathrm{ml}$. The calibration equation was: $\mathrm{AU}=-4443+$ $44599 \mathrm{C}(\mathrm{r}=0.9998)$, where $\mathrm{AU}$ is the detector signal, $\mathrm{C}$ is the concentration of $\mathrm{VRC}$, and $\mathrm{r}$ is the correlation coefficient. The high $r$ value was indicative for the good linearity, and the low values of standard deviations of the intercept and the slope were indicative for the

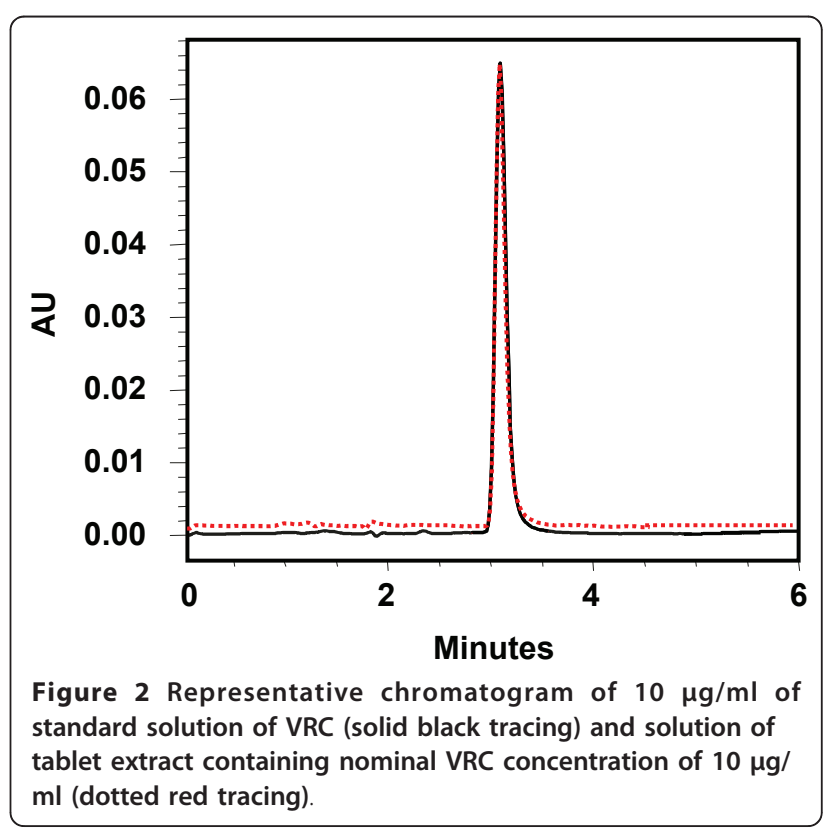


significant validity of the calibration points used for constructing the calibration curve.

The limit of detection (LOD) and limit of quantitation (LOQ) were calculated based on the signal-to-noise ratio [14]. The intercept was then equal to SD0 (the estimated SD at a concentration of zero). LOD was then defined as 3SD0, and LOQ was defined as 10SD0. The LOD and LOQ values were 0.11 and $0.38 \mu \mathrm{g} / \mathrm{ml}$, respectively.

\section{Precision}

Precision was measured in accordance with ICH recommendation. Five consecutive injections of VRC solution at three varying concentrations $(6,8$, and $10 \mu \mathrm{g} / \mathrm{ml})$ showed excellent repeatability (intra-day precision) as the relative standard deviation (RSD) of the signal values did not exceed $0.24 \%$ (Table 1 ). Inter-day precision (reproducibility) was determined by measuring inter-day variation for triplicate determination of VRC at the same VRC concentrations $(6,8$, and $10 \mu \mathrm{g} / \mathrm{ml})$. The low RSD values $(\leq 0.34 \%)$ indicated the acceptable reproducibility of the method [14].

\section{Accuracy}

Accuracy was determined by the recovery study of known amounts $(6-12 \mu \mathrm{g} / \mathrm{ml})$ of VRC standard added to a placebo matrix for tablets. The samples were analyzed ( 5 replicates were injected) by one analyst, and the added amounts were calculated from a calibration curve. The recovery was presented as percentages, (calculated concentration/nominal concentration $\times 100$ ). The recovery values ranged from 98.63 to 101.19 ( \pm 0.22 $0.55 \%)$, Table 2 . These results indicated the acceptable accuracy of the method [14].

\section{Robustness and Ruggedness}

In order to measure the extent of the method robustness, the most critical parameters were interchanged while keeping the other parameters unchanged, and in parallel the chromatographic profile was observed and recorded. The chromatographic parameters were interchanged within the range of $1-10 \%$ of the optimum recommended conditions. The studied parameters were: the composition of the mobile phase, $\mathrm{pH}$, flow rate, and column temperature. The results indicated that the small change in the conditions did not significantly affect the determination of VRC.

Ruggedness of the method was determined by using mobile phase components from two different manufactures. There was no significant change in the retention time of VRC was observed; RSD was 0.24 $0.37 \%$ indicating the ruggedness of the method.

\section{Sample Solution Stability}

The stability of the drug in solution during analysis was determined by repeated analysis of samples during the course of experimentation on the same day and also after storage of the drug solution $(8 \mu \mathrm{g} / \mathrm{ml})$ for 24,48 and 72 hours under laboratory bench condition $\left(25 \pm 1^{\circ}\right.$ C) and under refrigeration $\left(8 \pm 0.5^{\circ} \mathrm{C}\right)$. There was no significant change in analysis over a period of 72 hours. The mean RSD between peak areas for the samples stored under refrigeration $\left(8 \pm 1^{\circ} \mathrm{C}\right)$ and at laboratory temperature $\left(25 \pm 1^{\circ} \mathrm{C}\right)$ was found to be $0.47 \%$ and $0.24 \%$, respectively, suggesting that the drug solution can be stored without any degradation over the time interval studied.

\section{System Suitability Tests}

The chromatographic systems used for analysis must pass the system suitability limits before sample analysis can commence. The capacity factor (K), injection repeatability (as described earlier in the subsection, precision), tailing factor $(\mathrm{T})$, theoretical plate number $(\mathrm{N})$ and resolution (Rs) for the principle peak and its degradation product were evaluated using VRC solution of 8 $\mu \mathrm{g} / \mathrm{ml}$. The capacity factor $(\mathrm{K})$ was found to be 1.99 indicating that the VRC peak is well resolved with respect to the void volume. The RSD of five consecutive injections was found to be $0.24 \%$, indicating good injection repeatability. The tailing factor (T) for VRC peak was found to be 1.25 , reflecting good peak symmetry. The resolution (Rs) for the principle peak and degradation product was found to be 1.87 , indicating good separation of the drug from degradation product. The theoretical plate number $(\mathrm{N})$ was found to be 1179 for the column used in the study $(150 \mathrm{~mm} \times 4.6 \mathrm{~mm}$ i.d., particle size $5 \mu \mathrm{m})$, thus demonstrating acceptable column efficiency. All these results assure the adequacy of the proposed HPLC method for routine analysis of VRC.

\section{Stability-Indicating Study}

The ICH guideline entitled stability testing of drug substances and products [14] requires the stress testing to be carried out to elucidate the inherent stability characteristics of the active substance, and provide a rapid identification of differences that might result from

Table 1 Precision of the proposed method

\begin{tabular}{lllll}
\hline Concentration level $(\boldsymbol{\mu g} / \mathrm{ml})$ & Intra-day precision & \multicolumn{3}{l}{ Inter-day precision } \\
\cline { 2 - 5 } & Peak area $($ mean \pm SD) & RSD (\%) & Peak area (mean \pm SD) & RSD (\%) \\
\hline 6 & $256980 \pm 568.4$ & 0.22 & $259606 \pm 1588$ & 0.61 \\
8 & $351882 \pm 1182$ & 0.34 & $358161 \pm 865.7$ & 0.24 \\
10 & $436126 \pm 388.6$ & 0.09 & $463025 \pm 1316$ & 0.28 \\
\hline
\end{tabular}


Table 2 Evaluation of the method accuracy by recovery study

\begin{tabular}{lll}
\hline Added concentration $(\boldsymbol{\mu g} / \mathrm{ml})$ & $\begin{array}{l}\text { Found concentration } \\
(\boldsymbol{\mu} \mathbf{g} / \mathbf{m l} \pm \mathbf{S D})\end{array}$ & $\begin{array}{l}\text { Recovery } \\
(\% \pm \mathrm{RSD})\end{array}$ \\
\hline 6 & $5.92 \pm 0.03$ & $98.6 \pm 0.55$ \\
8 & $8.01 \pm 0.02$ & $100.1 \pm 0.22$ \\
10 & $10.05 \pm 0.03$ & $100.5 \pm 0.30$ \\
12 & $12.14 \pm 0.04$ & $101.2 \pm 0.33$ \\
\hline
\end{tabular}

a Values are mean of 5 determinations \pm RSD.

changes in the manufacturing processes or source sample. Susceptibility to oxidation, hydrolytic, and photolytic stability are the required tests. An ideal stability-indicating method is one that quantifies the standard drug alone and also resolves its degradation products. As described in the experimental section, different stress conditions were applied: boiling, acid, base hydrolysis, oxidation, and irradiation with UV light. From this investigation, it was clear that in case of boiling, UV irradiation (solid state and solution), and oxidation, VRC was stable under the employed stress conditions as no degradation products were observed in their chromatograms, which were identical to the chromatogram of VRC solution that has not been subjected to any stress conditions (Figure 3A). In case of acid hydrolysis and alkaline hydrolysis degradation products were observed at retention times of 1.46 and $1.37 \mathrm{~min}$, respectively (Figure 3B-D). In both cases, the method was able to separate completely the degradation products from the intact VRC. This confirmed the selectivity and stability-indicating property of the proposed method. The concentration of the produced degradation products relative to the intact VRC was calculated and found to be 0.29 and $0.31 \%$ in case alkaline hydrolysis and acid hydrolysis, respectively.

\section{Applicability of the Method}

It is evident from the results obtained previously that the proposed method gave satisfactory results with the analysis of VRC in bulk. Thus, VRC-containing tablets were subjected to the analysis by the proposed method. The label claim percentage was $99.7 \pm 0.32 \%$. This acceptable value indicated the applicability of the method for the routine quality control of VRC tablets without interference from the excipients. This was evidenced from the good label claim percentage as well as the absence of any peaks in the chromatogram of the tablet extract solution (Figure 2).

\section{Experimental}

\section{Materials}

Varenicline Tartarate reference standard with claimed purity of $99.6 \%$ was purchased from Weihua Pharma Co. Ltd. (Zhejiang, China). Champix ${ }^{\circledR}$ tablets (Pfizer Inc,

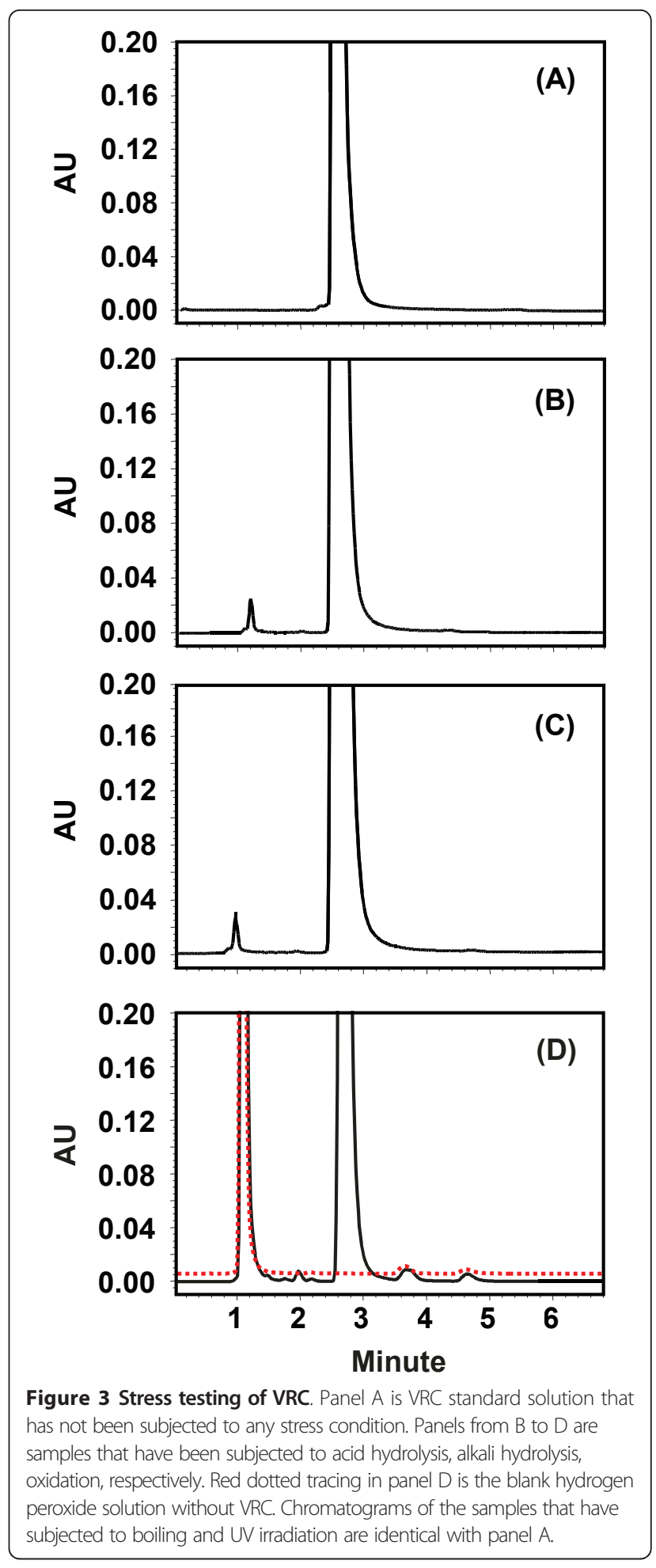

New York, USA), labeled to contain $1 \mathrm{mg}$ (as the anhydrous base) per tablet was obtained from the local market. HPLC-grade solvents, and reagent-grade sodium hydroxide, hydrochloric acid, hydrogen peroxide, potassium dihydrogen phosphate and orthophosphoric acid 
were purchased from Merck (Darmstadt, Germany). Distilled water purified by a Millipore Milli- $Q^{\circledR}$ UF Plus apparatus (Millipore, Molsheim, France) was used throughout the work.

\section{Chromatographic system}

HPLC apparatus consisted of a Waters Alliance HPLC systems (Waters, USA) equipped with 2996 photodiode array (PDA) detector. The chromatographic separations were performed on a Zorbax Eclipse XDB-C8 column $(150 \mathrm{~mm} \times 4.6 \mathrm{~mm}$ i.d., particle size $5 \mu \mathrm{m})$ manufactured by Millipore, USA. The column temperature was kept constant at $25 \pm 2^{\circ} \mathrm{C}$. Separations were performed in isocratic mode using a mobile phase consisted of acetonitrile and $50 \mathrm{mM}$ potassium dihydrogen phosphate buffer $(10: 90, v / v)$, and an apparent $\mathrm{pH}$ adjusted to $3.5 \pm 0.1$ with $10 \%$ phosphoric acid solution. The mobile phase was filtered by a Millipore vacuum filtration system equipped with a $0.45 \mu \mathrm{m}$ filter, degassed by ultrasonic bath, and by bubbling helium gas for $5 \mathrm{~min}$ prior to its use. The flow rate of the mobile phase was 1 $\mathrm{ml} / \mathrm{min}$, and the sample injection volume was $10 \mu \mathrm{l}$. The PDA detector was set at $235 \mathrm{~nm}$. Peak identity was confirmed by retention time comparison and comparison of the spectra obtained from the PDA detector.

\section{Preparation of standard and sample solutions}

An accurately weighed quantity $(25 \mathrm{mg}$ ) of VRC reference standard material was transferred to a $25-\mathrm{ml}$ volumetric flask, and dissolved in $25 \mathrm{ml}$ water. This stock solution $(1 \mathrm{mg} / \mathrm{ml})$ was further diluted with water to produce a working standard solution of $8 \mu \mathrm{g} / \mathrm{ml}$. Tablets sample was prepared as the following: 20 tablets were weighed and the average weight was calculated. Tablets were crushed to a fine powder, and a quantity of the powdered tablets, equivalent to $10 \mathrm{mg}$ of VRC, was transferred to $50 \mathrm{ml}$ volumetric flasks. A $25 \mathrm{ml}$ of methanol was added, the contents of the flask were shaken for 10 min by a mechanical shaker, and the volume was diluted to $50 \mathrm{ml}$ with methanol. This solution $(0.5$ $\mathrm{mg} / \mathrm{ml}$ ) was diluted to give a concentration $10 \mu \mathrm{g} / \mathrm{ml}$. This solution was filtered through a $0.45 \mu \mathrm{m}$ membrane filter and the filtrate was subjected to the analysis by the proposed method.

\section{Forced degradation Boiling}

One milliliter of VRC solution $(25 \mathrm{mg} / \mathrm{ml})$ was transferred to a small rounded flask. The solution was subjected to reflux for $2 \mathrm{~h}$ in a boiling water bath. The solution was cooled to room temperature $\left(25 \pm 5^{\circ} \mathrm{C}\right)$, and a volume of $10 \mu \mathrm{l}$ ( $1 \mathrm{mg}$ sample) was injected into the HPLC system.

\section{Acid and alkali hydrolysis}

Aliquot of $1 \mathrm{ml}$ of VRC solution $(25 \mathrm{mg} / \mathrm{ml})$ was transferred to a small rounded flask. The solution was mixed with $4 \mathrm{ml}$ of $0.1 \mathrm{~N}$ hydrochloric acid, or $0.1 \mathrm{~N}$ sodium hydroxide. The prepared solutions were subjected to reflux for $2 \mathrm{~h}$ in a boiling water bath. The samples were cooled to room temperature $\left(25 \pm 5^{\circ} \mathrm{C}\right)$, neutralized with an amount of acid or base equivalent to that of the previously added. From the resulting neutral solution, $10 \mu \mathrm{l}$ $(1 \mathrm{mg})$ was injected into the HPLC system.

\section{Oxidation}

One milliliter of VRC solution $(25 \mathrm{mg} / \mathrm{ml})$ was transferred to rounded flask. The contents were then mixed with $4 \mathrm{ml}$ of $30 \%$ hydrogen peroxide solution, and the reaction mixture was allowed to proceed at room temperature $\left(25 \pm 5^{\circ} \mathrm{C}\right)$ for $2 \mathrm{~h}$ with intermittent shaking. A volume of $10 \mu \mathrm{l}(1 \mathrm{mg})$ was injected into the HPLC system

\section{Irradiation with ultraviolet light}

A sample powder of VRC ( $25 \mathrm{mg}$ ) was exposed to UV light $(245 \mathrm{~nm})$ for 72 hours. The material was dissolved in $5 \mathrm{ml}$ water. The solution was filtered with syringe filtration disk and diluted to $25 \mathrm{ml}$ with suitable solvent to obtain a claimed concentration of $1 \mathrm{mg} / \mathrm{ml}$. A volume of $10 \mu \mathrm{l}$ was injected into the HPLC system. As well, an aqueous solution of VRC $(1 \mathrm{mg} / \mathrm{ml})$ was exposed to UV light $(245 \mathrm{~nm})$ for 72 hours, and then $10 \mu \mathrm{l}$ was injected into the HPLC system

\section{Conclusions}

The present study represents the first report that deals with the development of a stability-indicating HPLC method for determination of VRC. This study is a typical example of development of a stability-indicating assay, established following the recommendations of ICH/FDA guidelines. The proposed method showed acceptable accuracy, precision, selectivity, and wide linear concentration range. From the economical point of view, the method involved the native UV-absorbing property of VRC, rather than expensive derivatizing analytical reagents. Statistical analysis for the results proved that the method is suitable for the determination of VRC in bulk and tablet forms without any interference from the degradation products, and it is recommended for routine use in quality control industry laboratories.

\section{Abbreviations}

HPLC: high-performance liquid chromatography; VRC: varenicline; ICH: International Conference on Harmonization; FDA: Food and Drug Administration; UV: ultraviolet; $\lambda_{\max }$ : maximum absorption peak; LOD: limit of detection; LOQ: limit of quantification; SD: standard deviation; RSD: relative standard deviation; PDA: photodiode array. 


\section{Acknowledgements}

The authors extend their appreciation to the Deanship of Scientific Research at King Saud University for funding the work through the research group No. RGP-VPP-065.

\section{Authors' contributions}

AK participated in the design of the study and preparing the draft manuscript. MM carried out the optimization of chromatographic conditions and stability testing. MK participated in stability testing and application of the method. ID participated in the study design, statistical analysis of the data and preparing the manuscript.

\section{Competing interests}

The authors declare that they have no competing interests.

Received: 6 May 2011 Accepted: 14 June 2011 Published: 14 June 2011

\section{References}

1. Rollema H, Chambers LK, Coe JW, Glowa J, Hurst RS, Lebel LA, Lu Y, Mansbach RS, Mather RJ, Rovetti CC, Sands SB, Schaeffer E, Schulz DW, Tingley III FD, Williams KE: Pharmacological profile of the alpha4beta2 nicotinic acetylcholine receptor partial agonist varenicline, an effective smoking cessation aid. Neuropharmacol 2007, 52:985-994.

2. Dani JA, De Biasi M: Cellular mechanisms of nicotine addiction. Pharmacol Biochem Behav 2001, 70:439-446.

3. Picciotto MR, Zoli M, Rimondini R, Léna C, Marubio LM, Pich EM, Fuxe K, Changeux JP: Acetylcholine receptors containing the beta2 subunit are involved in the reinforcing properties of nicotine. Nature 1998, 391:173-177.

4. Tapper AR, McKinney SL, Nashmi R, Schwarz J, Deshpande P, Labarca C, Whiteaker P, Marks MJ, Collins AC, Lester HA: Nicotine activation of alpha4* receptors: sufficient for reward, tolerance, and sensitization. Science 2004, 306:1029-1032.

5. Zieler-Brown L, Kyle J: Oral varenicline for smoking cessation. Ann Pharmacother 2007, 41:95-99.

6. Chantix: Package Insert. New York, NY: Pfizer Inc; 2008.

7. Ahuja S, Alsante KM: Handbook of Isolation and Characterization of Impurities in Pharmaceuticals Academic Press, San Diego; 2003.

8. Ahuja S: Impurities Evaluation of Pharmaceuticals Marcel Dekker, Inc., New York; 1998.

9. FDA: Guidance for Industry: Impurities in Drug Product, Draft guidance. U.S. Department of Health and Human Services, Food and Drug Administration, Center for Drug Evaluation and Research (CDER); 1998

10. Grimm W, Carstensen JT, Rhodes CT, Eds: Drug Stability, Principles and Practices Marcel Dekker, Inc., New York; 2002, 520.

11. Khan H, Ali M, Ahuja A, Ali J: Stability Testing of Pharmaceutical Products - Comparison of Stability Testing Guidelines. Current Pharm. Anal 2010 6:142-150.

12. ICH Guidance for Industry: Q1A (R2): Stability Testing of New Drug Substances and Products IFPMA, Geneva; 2000.

13. Satheesh B, Kumarpulluru S, Raghavan V, Saravanan D: UPLC separation and quantification of related substances of varenicline tartarate tablet. Acta Chromatographica 2010, 22:207-218.

14. ICH Guideline: Q2 (R1): Validation of Analytical Procedure: Text and Methodology. ICH, London; 2005.

\section{Publish with ChemistryCentral and every scientist can read your work free of charge \\ "Open access provides opportunities to our colleagues in other parts of the globe, by allowing anyone to view the content free of charge." \\ W. Jeffery Hurst, The Hershey Company. \\ - available free of charge to the entire scientific community \\ - peer reviewed and published immediately upon acceptance \\ - cited in PubMed and archived on PubMed Central \\ - yours - you keep the copyright \\ Submit your manuscript here: \\ http://www.chemistrycentral.com/manuscript/<smiles>c1ccccc1</smiles> ChemistryCentral}

